\title{
Correlation of systolic pressure variation, pulse pressure variation and stroke volume variation in different preload conditions following a single dose mannitol infusion in elective neurosurgical patients
}

\author{
Ganesamoorthi Arimanickam, Sethuraman Manikandan ${ }^{1}$
}

\begin{abstract}
Background: A Prospective observational study was designed assess the correlation between arterial pressure waveform derived indices and echocardiography derived stroke volume variation (SVV) at different preload conditions in patients undergoing elective craniotomies. Methods: Systolic pressure variation (SPV) and pulse pressure variation (PPV) were calculated from the arterial waveform. SVV was measured from transoesophageal echocardiography. After measuring baseline values for all three parameters, I g/kg of mannitol infusion (20\%) was given over 15-20 min. Repeated measurements of SPV, PPV, SVV, urine output and peak airway pressure were done at the interval of 15, 30, 60, 90 and 120 min after stopping mannitol infusion. Pearson correlation coefficient (level of significance), and receiver operating characteristics curve were used for statistical analysis. Results: Significant correlation was present between SPV and SVV throughout the study. Significant correlation between SPV and PPV was present only at $90 \mathrm{~min}$ and $2 \mathrm{~h}$ after mannitol. The predictive effect of SPV and PPV in differentiating a volume loss $\geq 10 \mathrm{~mL} / \mathrm{kg}$ was better than SVV.The best cut-off values for SPV, PPV and SVV were $12 \%, 9 \%$ and $20 \%$, respectively. Conclusions: During mechanical ventilation with a tidal volume of $8 \mathrm{~mL} / \mathrm{kg}$, SPV correlated significantly with SVV at different preload conditions following mannitol infusion. PPV correlated poorly with SVV. SPV and PPV correlated only in the presence of hypovolaemia.
\end{abstract}

Key words: Dynamic indices, pulse pressure variation, stroke volume variation, systolic pressure variation

\section{INTRODUCTION}

Volume status of the patients can be assessed using static or dynamic indices. Static indices are filling

Department of Anaesthesiology and Intensive Care, Meenakshi Hospital, Thanjavur, Tamil Nadu, ${ }^{1}$ Department of Anaesthesiology, Sree Chitra Tirunal Institute for Medical Sciences and Technology, Trivandrum, Kerala, India

Address for correspondence:

Dr. Ganesamoorthi Arimanickam, Department of Anaesthesiology and Intensive Care, Meenakshi Hospital, Thanjavur, Tamil Nadu, India. E-mail: drarimanickam@gmail.com

\begin{tabular}{|l|l|}
\hline \multicolumn{2}{|c|}{ Access this article online } \\
\hline Quick Response Code: & Website: \\
\hline & www.jnaccjournal.org \\
\hline & \\
\hline & \\
\hline
\end{tabular}

pressures such as central venous pressure (CVP) and pulmonary artery occlusion pressure. An accurate measure of preload at a given point of time does not necessarily reflect preload responsiveness, which is more important for a clinician. It is universally accepted that these filling pressures have little correlation with fluid responsiveness. ${ }^{[1]}$

Intermittent positive pressure ventilation of lung induces cyclic changes in left ventricular stroke volume (SV) ${ }^{[2]}$ The positive pleural pressure during inspiration decreases

This is an open access article distributed under the terms of the Creative Commons Attribution-NonCommercial-ShareAlike 3.0 License, which allows others to remix, tweak, and build upon the work non-commercially, as long as the author is credited and the new creations are licensed under the identical terms.

For reprints contact: reprints@medknow.com

How to cite this article: Arimanickam G, Manikandan S. Correlation of systolic pressure variation, pulse pressure variation and stroke volume variation in different preload conditions following a single dose mannitol infusion in elective neurosurgical patients. J Neuroanaesthesiol Crit Care 2016;3:219-26. 
right ventricular SV. ${ }^{[3]}$ The corresponding change in left ventricular SV is reflected during expiration due to the delay of pulmonary transit time. ${ }^{[4]}$ During mechanical ventilation, left ventricular SV decreases during expiration and increases during inspiration. ${ }^{[5]}$

The magnitude of variation in left ventricular SV within a respiratory cycle denotes preload dependency of the cardiovascular system. ${ }^{[6]}$ It is similar to the application of 'microfluid challenge' in a controlled and reversible manner and measuring the haemodynamic response. Based on this concept many dynamic indices predicting preload dependency of the cardiovascular system has been defined. SV variation (SVV), ${ }^{[7,8]}$ systolic pressure variation (SPV), ${ }^{[9]}$ delta down pressure ${ }^{[10]}$ and pulse pressure variation (PPV) ${ }^{[11,12]}$ are the commonly used dynamic indices. Apart from variation in left ventricular $\mathrm{SV}$, these dynamic indices are affected by tidal volume, ${ }^{[13-15]}$ airway pressure, ${ }^{[16]}$ respiratory rate ${ }^{[17]}$ and vasomotor tone. ${ }^{[18]}$ Systolic and PPVs can be measured by online ${ }^{[19]}$ or offline ${ }^{[20]}$ analysis of arterial pressure waveform. Offline measurement of systolic and PPVs using Datex Ohmeda S/5 multi-parameter monitor had been described by Gouvea and Gouvea.

SVV can be assessed by pulse contour analysis (arterial catheter) ${ }^{[12]}$ or aortic blood flow velocity (echocardiography) waveforms. ${ }^{[21]}$ Using echocardiography SVV is obtained from respiratory changes in velocity time integral (VTI) of aortic blood flow through left ventricular outflow tract. ${ }^{[21]}$

We decided to study the correlation between arterial pressure waveform derived indices and echocardiography derived SVV in patients undergoing elective craniotomies. Repeated measurement of these variables following mannitol infusion can be done to assess their correlation at different preload conditions.

\section{METHODOLOGY}

The primary objective of this study was to assess the correlation of SPV, PPV and SVV in different preload conditions following a single dose mannitol infusion in neurosurgical patients undergoing elective supratentorial craniotomies. Moreover, the secondary objective was to assess the correlation between these indices and volume loss in the form of urine output following mannitol infusion. Inclusion criteria were age $>16$ years and $<70$ years, American Society of Anesthesiology Grade I and II and elective supratentorial craniotomies. Exclusion criteria were cardiac rhythm other than sinus, contraindications for transoesophageal echocardiography (history of swallowing difficulty, oesophageal surgery, strictures, mass lesions or abnormalities), intraoperative patient position other than supine and presence of any cardiac (valvular heart disease, intracardiac shunts, peripheral vascular disease) or lung (such as asthma, chronic obstructive pulmonary disease and tuberculosis) pathologies.

\section{Materials}

SPV and PPV values were measured from an arterial waveform obtained in Philips V24E multi-parameter monitor. SVV was measured by transoesophageal echocardiography, using multi-plane transoesophageal echocardiography (TEE) probe (9T; 4.0-10.0 MHz) in GE Vivid 7 machine.

\section{Sample size calculation}

A pilot study consisting of 11 patients was conducted. Baseline values of SPV, PPV and SVV were measured. Mean \pm standard deviation at baseline for SPV, PPV and SVV were $7 \pm 1.7564,4 \pm 1.20511$ and $13 \pm 4.8382$, respectively. Pearson correlation coefficient between SPV and SVV was 0.36973 and between PPV and SVV was 0.37342 . Correlation table was referred to find out the appropriate sample size. ${ }^{[22]}$ After fixing the level of significance at 0.01 , for the two-tailed Pearson correlation coefficient of 0.35 , the sample size was found to be 52 .

\section{Methods}

After obtaining approval from department review board and informed consent, 54 consecutive patients undergoing elective craniotomies who satisfied inclusion and exclusion criteria were included in the study.

\section{Anaesthesia management}

Patients received premedication on the morning of surgery according to treating consultant's discretion. Inside the operation theatre, non-invasive monitors such as pulse oximetry $\left(\mathrm{SpO}_{2}\right)$, electrocardiogram (ECG) and non-invasive blood pressure were attached and baseline values were recorded. After securing intravenous access, anaesthesia was induced with sodium thiopentone $5 \mathrm{mg} / \mathrm{kg}$ intravenously. For facilitating endotracheal intubation vecuronium $0.12 \mathrm{mg} / \mathrm{kg}$ and fentanyl $2 \mu \mathrm{g} / \mathrm{kg}$ were administered. The airway was secured using appropriate size endotracheal tube. Anaesthesia was maintained with the air-oxygen mixture and $1 \%$ isoflurane. All patients were control ventilated with a fixed tidal volume of $8 \mathrm{~mL} / \mathrm{kg}$ and positive end-expiratory pressure of zero. End-tidal carbon dioxide was monitored and maintained between 30 and $35 \mathrm{mmHg}$ by adjusting the respiratory rate. In all patients, radial artery cannulation was done for invasive blood pressure monitoring (using a $20 \mathrm{G}$ BD Insite $\mathrm{W}^{\mathrm{TM}}$ cannula). After securing all invasive lines and before positioning patients using clamps, TEE probe was inserted, and baseline cardiac status was assessed. Once the patients were positioned crystalloid intravenous fluids (normal saline or lactated Ringer's solution) were given at the rate of 4-6 mL/kg/h. Fluid boluses of $100 \mathrm{~mL}$ were given if mean arterial pressure decreased $\leq 60 \mathrm{mmHg}$ or $\geq 20 \%$ 
from the baseline value. Fentanyl at the dose of $1 \mu \mathrm{g} / \mathrm{kg} / \mathrm{h}$ was given as an infusion. Stable anaesthetic depth was established by maintaining constant MAC value.

\section{Observations}

Measurements of baseline values for SPV, PPV and SVV were done. Mannitol infusion (20\%) at the dose of $1 \mathrm{~g} / \mathrm{kg}$ was started during first burr hole placement and it was given over 15-20 min. Repeated measurements of $\mathrm{SPV}, \mathrm{PPV}, \mathrm{SVV}$, urine output and peak airway pressure were done at the interval of 15, 30, 60, 90 and $120 \mathrm{~min}$ after stopping mannitol infusion.

\section{Measurement of systolic pressure variation and pulse pressure variation}

To measure SPV and PPV, arterial pressure waveform label in the monitor was changed to pulmonary artery pressure [Figure 1, Step 1]. After optimising the scale, 'Procedure' option was selected from menu. Among various procedures, 'Wedge' option was selected [Figure 1, Step 2]. Once arterial pressure waveforms corresponding to consecutive three respiratory cycles were obtained in procedure screen, tracing was stopped by selecting 'stop trace' option [Figure 1, Step 3]. In this monitor, simultaneous respiratory waveforms were obtained from ECG electrodes. Next 'edit wedge' option was selected. A cursor (horizontal line) appeared in procedure screen which can be moved up and down and pressure value corresponding to cursor position would be shown [Figure 1, Step 4]. This was used to obtain maximum and minimum values for systolic and diastolic pressure in a single respiratory cycle. SPV and PPV were calculated using following formulae.

$$
\mathrm{SPV} \%=100 \times\left(\mathrm{SBP}_{\max }-\mathrm{SBP}_{\min }\right) /\left(\mathrm{SBP}_{\max }+\mathrm{SBP}_{\min }\right) / 2 \%
$$

$$
\begin{aligned}
\mathrm{PPV} \%= & 100 \times\left(\mathrm{PP}_{\max }-\mathrm{PP}_{\min }\right) /\left(\mathrm{PP}_{\max }+\mathrm{PP}_{\min }\right) / 2 \% . \\
\mathrm{PPV} \%= & 100 \times\left([\mathrm{SBP}-\mathrm{DBP}]_{\max }-[\mathrm{SBP}-\mathrm{DBP}]_{\min }\right) / \\
& \left([\mathrm{SBP}-\mathrm{DBP}]_{\max }+[\mathrm{SBP}-\mathrm{DBP}] \min \right) / 2 \% .
\end{aligned}
$$

Where,

SBP: Systolic blood pressure,

DBP: Diastolic blood pressure,

PP: Pulse pressure.

\section{Measurement of stroke volume variation}

Measurement of SVV was done using trans-aortic Doppler flow velocities. For obtaining this, the multi-plane probe was positioned in deep transgastric aortic long axis view. After ruling out stenosis or regurgitation at aortic valve $(\mathrm{AV})$, screen was frozen at $\mathrm{AV}$ opening and $\mathrm{AV}$ diameter was measured [Figure 2, Step 1]. Then cursor for pulse wave Doppler was placed on the aortic side of AV and tracing obtained. Baseline and horizontal sweep speed were adjusted and VTI waveform trace, corresponding to 3 or 4 respiratory cycles was obtained and the screen was frozen. Maximum and minimum SV values in each respiratory cycle were measured [Figure 2, Step 2]. SVV was calculated using following formulae.

$\mathrm{SVV} \%=100 \times\left(\mathrm{SV}_{\text {max }}-\mathrm{SV}_{\text {min }}\right) /\left(\mathrm{SV}_{\text {max }}+\mathrm{SV}_{\text {min }}\right) / 2 \%$

Once the appropriate waveforms were obtained, both the monitors' screens were frozen at the same time and the values were noted.

\section{RESULTS}

Demographic data are shown in Table 1. As shown in Figure 3, SPV and SVV slightly decreased initially at

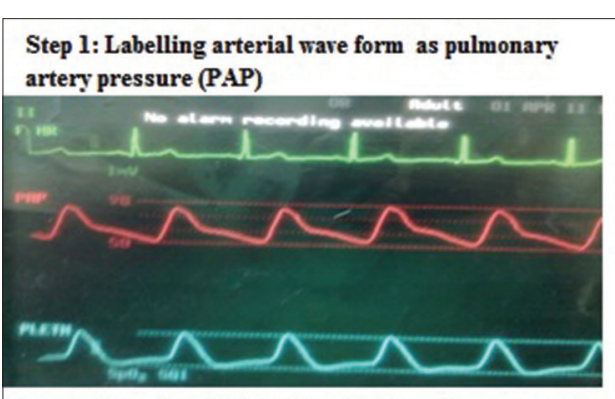

Step 2: Selecting "Wedge" option from the menu at the bottom of the screen

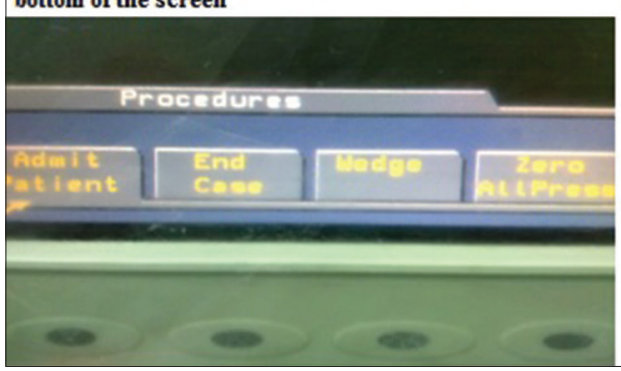

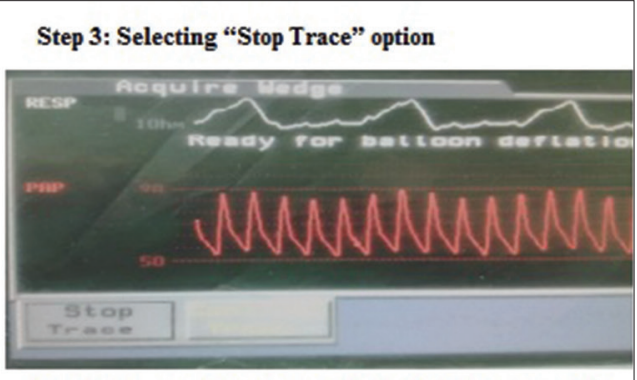

Step 4: Cursor (white horizontal line) and corresponding pressure value (number in white colour)

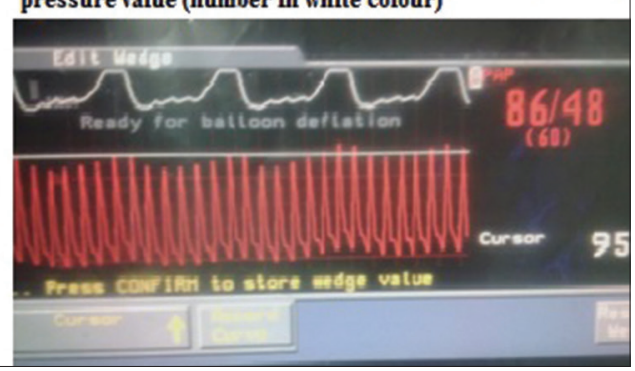

Figure 1: Measuring systolic and pulse pressure variation 


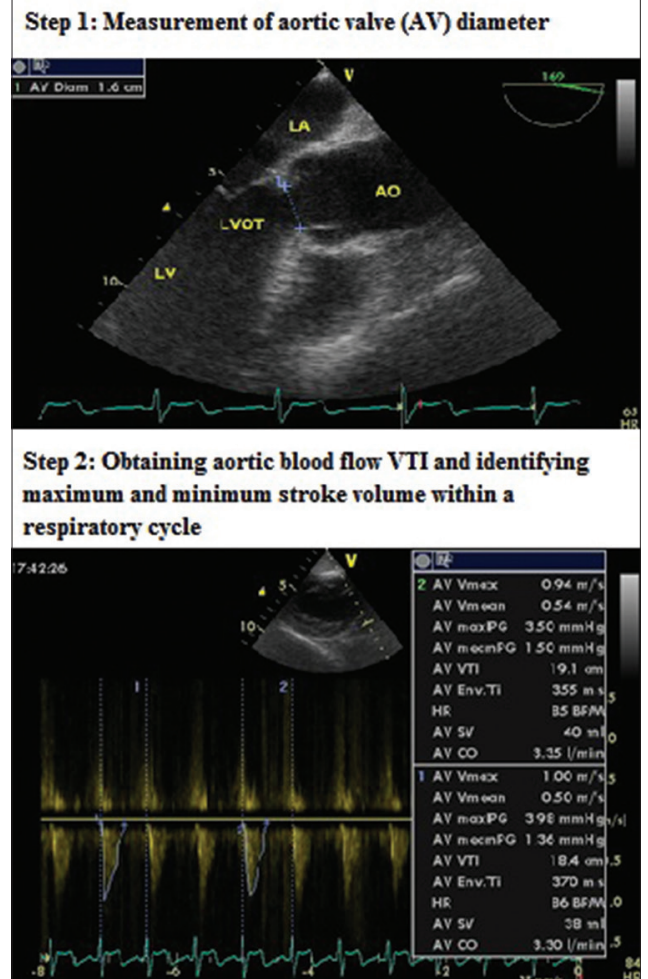

Figure 2: Measuring stroke volume variation

15 min after stopping mannitol infusion. Following that there was a continuing increase till $2 \mathrm{~h}$. PPV did not change during $15 \mathrm{~min}$, but thereafter started increasing similar to SPV. Urine flow rate was highest during the first $15 \mathrm{~min}$ and then gradually decreased till $2 \mathrm{~h}$ [Table 2].

Correlations among dynamic indices at different time intervals are shown in Table 3. Significant correlation was present between SPV and SVV throughout the study period. Significant correlation between SPV and PPV was present only at $90 \mathrm{~min}$ and $2 \mathrm{~h}$ after mannitol. PPV was poorly correlating with SVV at all-time intervals.

Correlations between values of dynamic indices and corresponding urine flow rate at different time intervals are shown in Table 4. Values of SVV and SPV correlated significantly with urine flow rate during first $15 \mathrm{~min}$. After $60 \mathrm{~min}$, correlation is not strong. Values of PPV correlated significantly with urine flow rate at 30 and $90 \mathrm{~min}$.

When the values of SPV, PPV and SVV at different time intervals were pooled together, they had a significant correlation with each other, in the order of between SPV and PPV > SPV and SVV > PPV and SVV [Table 5]. Same interaction can be graphically represented using scatter plot and line of fit [Figures 4-6]. The pooled values of SPV, PPV and SVV had a significant correlation with urine output, in the order of SPV > PPV > SVV [Table 6].

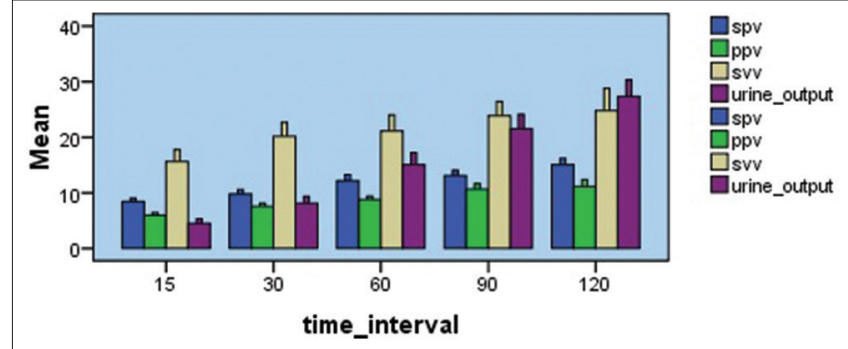

Figure 3: Error bar graph showing systolic pressure variation, pulse pressure variation, stroke volume variation and urine output per kilogram at different time intervals

Table 1: Demographic data

\begin{tabular}{lc}
\hline Parameters & Values \\
\hline Age (\%) & $2(3.7)$ \\
$16-20$ & $8(14.8)$ \\
$21-30$ & $11(20.4)$ \\
$31-40$ & $17(31.5)$ \\
$41-50$ & $12(22.2)$ \\
$51-60$ & $4(7.4)$ \\
$61-70$ & \\
Gender & $24: 30$ \\
Male: female & $64 \pm 10.11$ \\
Weight (in Kg, mean \pm SD) & \\
Surgery (\%) & $22(40.7)$ \\
Aneurysm & $2(3.7)$ \\
AVM & $14(26)$ \\
Gliomas & $7(13)$ \\
Meningiomas & $3(5.5)$ \\
Epilepsy & $6(11.1)$ \\
Others &
\end{tabular}

$\mathrm{SD}=$ Standard deviation, $\mathrm{AVM}=$ Arteriovenous malformation

Receiver operating characteristics (ROC) analysis of SPV, PPV and SVV values considering urine output $\geq 15 \mathrm{~mL} / \mathrm{kg}$ as the response criteria (which corresponds to approximately $10 \mathrm{~mL} / \mathrm{kg}$ volume loss) are shown in Table 7. The predictive effect of SPV and PPV in differentiating a volume loss $\geq 10 \mathrm{~mL} /$ $\mathrm{kg}$ was better than SVV. The best cut-off values for SPV, PPV and SVV were 12\%, 9\% and 20\%, respectively [Figure 7].

\section{DISCUSSION}

As the aim of the study was to find correlation among these dynamic indices at different loading conditions, establishing a significant change in preload at different time intervals would be a prerequisite. Considering a nearly constant fluid intake of $4-6 \mathrm{~mL} / \mathrm{kg} / \mathrm{h}$ during this study and a significant difference in urine output 
at different time intervals $(P<0.0001)$, different preload condition at each stage can be ascertained.

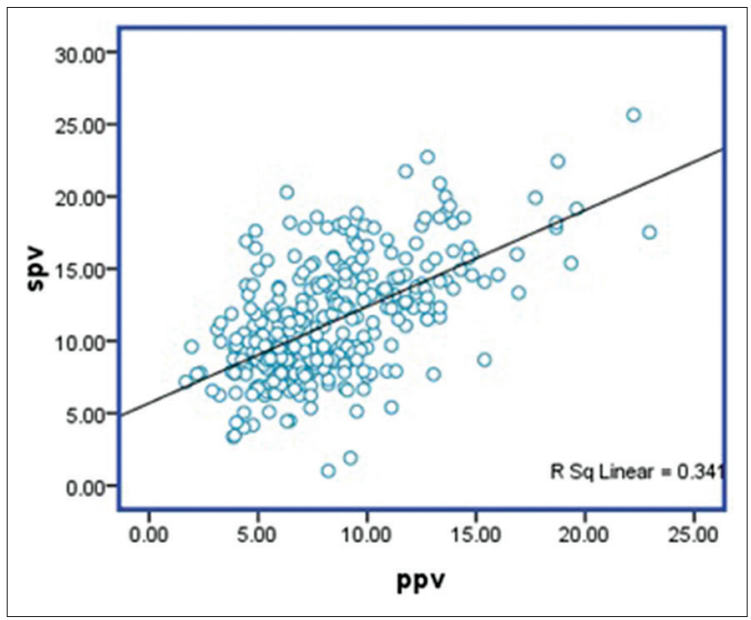

Figure 4: Scatter plot for systolic pressure variation and pulse pressure variation

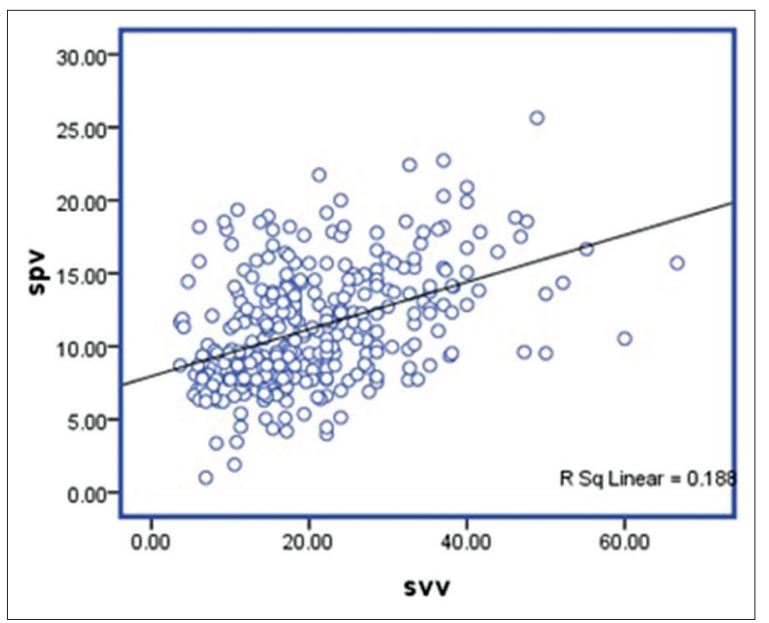

Figure 5: Scatter plot for systolic pressure variation and stroke volume variation

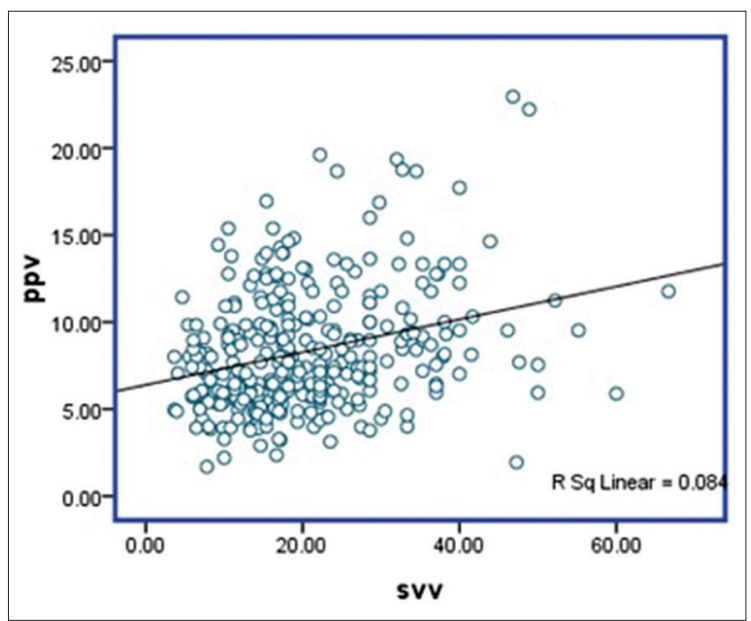

Figure 6: Scatter plot for pulse pressure variation and stroke volume variation
In this study following a single dose of mannitol infusion urine flow rate was highest during the first $15 \mathrm{~min}$, similar to previous reports. ${ }^{[23,24]}$ SPV and SVV decreased initially probably due to intravascular volume expansion but then increased significantly till the end of study indicating volume loss due to diuresis and these changes following mannitol have been reported earlier. ${ }^{[19]}$ Similar changes were not found in PPV.

Significant correlation was present between SPV and SVV values throughout the study period. Although SPV and PPV values increased as the negative fluid balance increased, a significant correlation between the values could be demonstrated only during $90 \mathrm{~min}$ and $2 \mathrm{~h}$ following mannitol. SVV and PPV values correlated poorly throughout the study period. But when data at different time intervals were pooled, all three indices correlated significantly with each other and also with urine output per kilogram. ROC curve analysis revealed better predictability of volume loss by SPV and PPV when compared to SVV.

Mannitol given in the dose of $1 \mathrm{~g} / \mathrm{kg}$ over 15-20 min produces relatively predictablechanges in haemodynamic status. ${ }^{[23-25]}$ An immediate cardiovascular effect of mannitol is a transient increase in cardiac output (CO) due to its direct effect on vascular tone. ${ }^{[25]}$ Mannitol has also been found to release histamine from basophils, which in turn causes a decline in systemic vascular resistance (SVR). ${ }^{[26]}$ CVP initially increases (within $15 \mathrm{~min}$ ) and starts to fall $30 \mathrm{~min}$ after administration of mannitol. ${ }^{[25]}$ After $45 \mathrm{~min}$, the cardiovascular status following mannitol infusion is dictated by the balance between the amount of intravascular volume contraction caused by diuresis and the amount of fluid intake. Such predictable changes in haemodynamic status in the $1^{\text {st }} \mathrm{h}$ following infusion render mannitol-induced intravascular changes 'a model for studying clinical situations with varying intravascular volume' ${ }^{[19]}$

Offline measurement of SPV and PPV as described by Gouvea and Gouvea had been validated by more than one study. ${ }^{[10-12]}$ SPV and PPV values expressed in $\mathrm{mmHg}$ had been shown to correlate significantly with the amount of volume loss following furosemide. ${ }^{[11]}$ SPV and PPV values expressed in percentage had been shown to correlate strongly with SVV measured using FloTrac/Vigileo monitor. ${ }^{[12]}$ SPV has been found to correlate well with an echocardiographic estimate of left ventricular end diastolic volume. ${ }^{[27]}$ SVV derived from FloTrac and Doppler measurements had been shown to have acceptable bias and limits of agreement and a similar performance regarding fluid responsiveness in patients undergoing liver transplantation. ${ }^{[28]}$

Although previous studies had found strong correlation among SPV, PPV and SVV, unlike in this study, they all 
Arimanickam and Manikandan: Correlation of systolic pressure variation, pulse pressure variation and stroke volume variation

Table 2: SPV, PPV, SVV, Urine output per Kg and Urine flow rate (mean \pm SD) at different time intervals

\begin{tabular}{|c|c|c|c|c|c|c|c|}
\hline \multirow[t]{2}{*}{ Variables } & \multicolumn{6}{|c|}{ Time intervals } & \multirow[t]{2}{*}{$P$ value ${ }^{*}$} \\
\hline & Baseline & $\begin{array}{l}\text { Fifteen } \\
\text { minutes }\end{array}$ & $\begin{array}{l}\text { Thirty } \\
\text { minutes }\end{array}$ & $\begin{array}{c}\text { Sixty } \\
\text { minutes }\end{array}$ & $\begin{array}{l}\text { Ninety } \\
\text { minutes }\end{array}$ & $\begin{array}{c}\text { Two } \\
\text { hours }\end{array}$ & \\
\hline SPV (\%) & $9.0264 \pm 2.2107$ & $8.4449 \pm 2.1934$ & $9.7898 \pm 2.9735$ & $12.1827 \pm 3.9204$ & $13.1006 \pm 3.5201$ & $15.0353 \pm 4.2133$ & 0.0001 \\
\hline PPV (\%) & $5.8182 \pm 1.4438$ & $5.9763 \pm 1.6471$ & $7.5507 \pm 2.2164$ & $8.8079 \pm 2.2224$ & $10.6443 \pm 3.6500$ & $11.1445 \pm 4.5407$ & 0.0001 \\
\hline SVV (\%) & $17.5162 \pm 9.1286$ & $15.6115 \pm 7.8832$ & $20.1618 \pm 9.1245$ & $21.1314 \pm 10.6392$ & $23.8831 \pm 9.3280$ & $24.7750 \pm 14.7624$ & 0.0001 \\
\hline $\begin{array}{l}\text { Urine output } \\
\text { per } \mathrm{Kg}\end{array}$ & - & $4.53 \pm 2.94$ & $3.62 \pm 2.50$ & $6.90 \pm 3.69$ & $6.48 \pm 3.32$ & $5.82 \pm 3.56$ & 0.0001 \\
\hline $\begin{array}{l}\text { Urine flow } \\
\text { rate }(\mathrm{mL} / \mathrm{Kg} / \mathrm{h})\end{array}$ & - & $18.12 \pm 11.77$ & $14.50 \pm 10.01$ & $13.84 \pm 7.34$ & $12.92 \pm 6.66$ & $11.23 \pm 6.02$ & 0.001 \\
\hline
\end{tabular}

*One way ANOVA. SPV=Systolic pressure variation, PPV=Pulse pressure variation, SVV=Stroke volume variation, $\mathrm{SD}=$ Standard deviation

Table 3: Pearson correlation co-efficient (level of significance) among dynamic indices at different time intervals

\begin{tabular}{lcccccc}
\hline Variables & Baseline & $\mathbf{1 5}$ minutes & $\mathbf{3 0}$ minutes & $\mathbf{6 0}$ minutes & $\mathbf{9 0}$ minutes & Two hours \\
& $\boldsymbol{r}(\boldsymbol{P})$ & $\boldsymbol{r}(\boldsymbol{P})$ & $\boldsymbol{r}(\boldsymbol{P})$ & $\boldsymbol{r}(\boldsymbol{P})$ & $\boldsymbol{r}(\boldsymbol{P})$ & $\boldsymbol{r}(\boldsymbol{P})$ \\
\hline SPV and PPV & $0.238(0.083)$ & $0.063(0.651)$ & $0.111(0.426)$ & $0.101(0.468)$ & $0.481^{* *}(0.000)$ & $0.631^{* *}(0.000)$ \\
SPV and SVV & $0.344^{*}(0.011)$ & $0.371^{* *}(0.006)$ & $0.179(0.196)$ & $0.525^{* *}(0.000)$ & $0.447^{* *}(0.001)$ & $0.242(0.078)$ \\
PPV and SVV & $0.201(0.144)$ & $0.178(0.198)$ & $0.177(0.199)$ & $0.092(0.509)$ & $0.156(0.261)$ & $0.162(0.243)$ \\
\hline
\end{tabular}

${ }^{*}$ Correlation is significant at the 0.05 level (2-tailed). ${ }^{* *}$ Correlation is significant at the 0.01 level (2-tailed). SPV=Systolic pressure variation, $\mathrm{PPV}=$ Pulse pressure variation, $\mathrm{SVV}=$ Stroke volume variation

Table 4: Pearson correlation co-efficient (level of significance) between dynamic indices and urine flow rate at different time intervals

\begin{tabular}{lccccc}
\hline Variables & \multicolumn{5}{c}{ Urine flow rate $\boldsymbol{r}(\boldsymbol{P})$} \\
\cline { 2 - 6 } & $\mathbf{1 5} \boldsymbol{\operatorname { m i n }} \boldsymbol{r}(\boldsymbol{P})$ & $\mathbf{3 0} \boldsymbol{\operatorname { m i n }} \boldsymbol{r}(\boldsymbol{P})$ & $\mathbf{6 0} \boldsymbol{\operatorname { m i n }} \boldsymbol{r}(\boldsymbol{P})$ & $\mathbf{9 0} \boldsymbol{\mathbf { m i n }} \boldsymbol{r}(\boldsymbol{P})$ & Two hours $\boldsymbol{r}(\boldsymbol{P})$ \\
\hline SPV & $0.331^{*}(0.014)$ & $0.200(0.148)$ & $0.051(0.714)$ & $0.079(0.568)$ & $0.149(0.283)$ \\
PPV & $0.133(0.133)$ & $0.293^{*}(0.032)$ & $0.146(0.293)$ & $0.269^{*}(0.049)$ & $0.097(0.485)$ \\
SVV & $0.854^{* *}(0.000)$ & $0.456^{* *}(0.001)$ & $0.248(0.071)$ & $0.020(0.887)$ & $0.083(0.550)$ \\
\hline
\end{tabular}

${ }^{*}$ Correlation is significant at the 0.05 level (2-tailed). ${ }^{*}$ Correlation is significant at the 0.01 level (2-tailed). SPV=Systolic pressure variation, $\mathrm{PPV}=$ Pulse pressure variation, $\mathrm{SVV}=$ Stroke volume variation

Table 5: Pearson correlation coefficient between pooled values of dynamic indices

\begin{tabular}{lccc}
\hline Variables & $\begin{array}{c}\text { SPV and } \\
\text { PPV }\end{array}$ & $\begin{array}{c}\text { SPV and } \\
\text { SVV }\end{array}$ & $\begin{array}{c}\text { PPV and } \\
\text { SVV }\end{array}$ \\
\hline$r(P)$ & $0.584^{* *}(0.000)$ & $0.434^{* *}(0.000)$ & $0.290^{* *}(0.000)$ \\
\hline
\end{tabular}

*Correlation is significant at the 0.05 level (2-tailed).

**Correlation is significant at the 0.01 level (2-tailed).

$\mathrm{SPV}=$ Systolic pressure variation, $\mathrm{PPV}=$ Pulse pressure

variation, $\mathrm{SVV}=$ Stroke volume variation

had used either PiCCO or FloTrac/Vigileo systems to determine SVV..$^{[8,12]}$ These monitoring systems use pulse contour analysis to derive SVV and CO.

In transoesophageal echocardiography, deep transgastric aortic long axis view provides optimal alignment of aortic blood flow and probe and it is considered as the ideal view for SV and CO measurements. ${ }^{[29]}$ Though there may be underestimation of absolute SV using transoesophageal echocardiography, ${ }^{[30]}$ the proportionate variation in SV during each respiratory cycle may be preserved. Greatest limiting factor in using TEE for measuring SV is the high influence of angle between the ultrasound beam and direction of blood flow. We avoided any probe manipulation during the study period. However, displacement of heart due to respiratory movements itself might change the angle of insonation within a respiratory cycle. This can introduce an error in the measurement of SVV using TEE.

Lack of correlation among these dynamic variables at some time intervals could be due to variation in the influence of SVR on these parameters. While SVV measured by echocardiography could be the least affected, PPV 
measured from arterial pressure trace could be the most affected one. Although affected by changes in SVR, SPV and PPV could still predict fluid responsiveness, as fall in SVR could be considered as 'relative hypovolaemia' of the expanded intravascular space and those patients also respond to fluid challenges. ${ }^{[7]}$ Furthermore, a volume loss of $10 \mathrm{~mL} / \mathrm{kg}$ or more in the form of urine output was better predicted by SPV and PPV values than that of SVV values. All the patients in this study received mannitol for the first time in operation theatre and the above finding cannot be generalised for patients on chronic mannitol therapy. The importance of replacing the urine output over time to avoid severe hypovolaemia needs to be emphasised.

\section{Limitations of the present study}

When we used $10 \mathrm{~mL} / \mathrm{kg}$ tidal volume transoesophageal echocardiographic view in the monitor was not stable

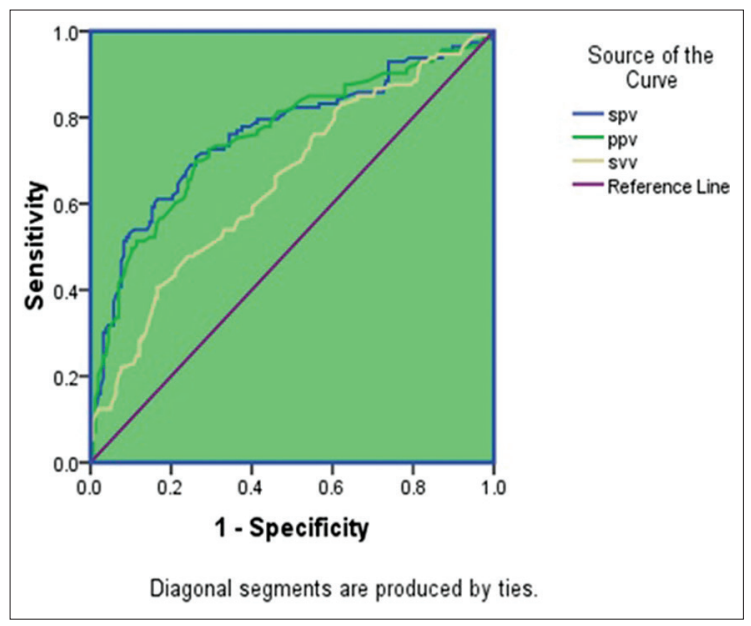

Figure 7: Receiver operating characteristics curve for systolic pressure variation, pulse pressure variation and stroke volume variation with urine output $\geq 15 \mathrm{ml} / \mathrm{kg}$ as response criteria

Table 6: Pearson correlation coefficient between pooled values of dynamic indices and urine output per $\mathrm{Kg}$

\begin{tabular}{|c|c|c|c|}
\hline Variables & SPV $r(P)$ & PPV $r(P)$ & SVV $r(P)$ \\
\hline $\begin{array}{l}\text { Urine output } \\
\text { per } \mathrm{Kg}\end{array}$ & $0.516^{* *}(0.000)$ & $0.496^{* *}(0.000)$ & $0.351^{* *}(0.000)$ \\
\hline $\begin{array}{l}{ }^{*} \text { Correlation } \\
{ }^{* *} \text { Correlation } \\
\text { SPV }=\text { Systolic } \\
\text { variation, SV }\end{array}$ & $\begin{array}{l}\text { significant a } \\
\text { significant } \\
\text { ressure vari } \\
=\text { Stroke volu }\end{array}$ & $\begin{array}{l}\text { e.05 level } \\
\text { e } 0.01 \text { level } \\
\text { n, PPV=Puls } \\
\text { variation }\end{array}$ & $\begin{array}{l}\text { ailed). } \\
\text { tailed). } \\
\text { oressure }\end{array}$ \\
\hline
\end{tabular}

in few patients. It changed considerably within each respiratory cycle due to respiratory movement of heart and pulse wave Doppler waveform was not obtained continuously. This may be because of the small size of thoracic cavity or more compliant lung resulting in more displacement of heart. Further De Backer et al. showed that PPV was a reliable predictor of fluid responsiveness only if the tidal volume was more than $8 \mathrm{~mL} / \mathrm{kg} .{ }^{[14]}$ With $8 \mathrm{~mL} / \mathrm{kg}$ tidal volume, we were able to get stable echocardiographic view throughout each respiratory cycle in all patients. SPV and PPV values had a significant correlation in $90 \mathrm{~min}$ and 2 $\mathrm{h}$ after mannitol. As correlation was getting stronger with increasing hypovolaemia, choosing a lesser tidal volume could be put forward as the reason for the absence of correlation among these dynamic indices at some point of time.

\section{CONCLUSION}

- During mechanical ventilation with a tidal volume of $8 \mathrm{~mL} / \mathrm{kg}$, SPV correlated significantly with SVV at different preload conditions following mannitol infusion. PPV correlated poorly with SVV. SPV and PPV correlated only in the presence of hypovolaemia when a low tidal volume $(8 \mathrm{~mL} / \mathrm{kg})$ is being used

- SVV and SPV correlated significantly with amount of volume loss in the form of urine output for the $1^{\text {st }} \mathrm{h}$ following mannitol infusion

- Systolic and PPVs predict a concomitant volume loss of $10 \mathrm{~mL} / \mathrm{kg}$ or more, better than SVV.

Although in general all three dynamic indices correlated with each other and the degree of volume loss, at different preload conditions, the strength of correlation varied. This may be because of variation in the influence of factors like SVR on these indices. Physicians should be aware of these limitations while employing these clinically useful indices.

\section{Acknowledgement}

Department of Anaesthesiology, Sree Chitra Tirunal Institute for Medical Sciences and Technology, Trivandrum, Kerala, India.

Financial support and sponsorship Nil.

Table 7: Receiver operating characteristics of SPV, PPV and SVV considering urine output $\geq 15 \mathrm{~mL} / \mathrm{Kg}$ as the response criteria

\begin{tabular}{lccccc}
\hline Variables & AUC $(\mathbf{9 5} \% \mathbf{C I})$ & Std.Error & Cut off values (\%) & Sensitivity & Specificity \\
\hline SPV & $0.762(0.702-0.823)$ & 0.031 & $12 \%$ & 0.717 & 0.726 \\
PPV & $0.755(0.695-0.816)$ & 0.031 & $9 \%$ & 0.655 & 0.758 \\
SVV & $0.651(0.585-0.717)$ & 0.034 & $20 \%$ & 0.558 & 0.637 \\
\hline
\end{tabular}

$\mathrm{SPV}=$ Systolic pressure variation, $\mathrm{PPV}=$ Pulse pressure variation, $\mathrm{SVV}=$ Stroke volume variation, $\mathrm{CI}=\mathrm{Confidence}$ interval, AUC $=$ Area under curve 


\section{Conflicts of interest}

There are no conflicts of interest.

\section{REFERENCES}

1. Marik PE, Baram M, Vahid B. Does central venous pressure predict fluid responsiveness? A systematic review of the literature and the tale of seven mares. Chest 2008;134:172-8.

2. Marik PE, Monnet X, Teboul JL. Hemodynamic parameters to guide fluid therapy. Ann Intensive Care 2011;1:1.

3. Morgan BC, Martin WE, Hornbein TF, Crawford EW, Guntheroth WG. Hemodynamic effects of intermittent positive pressure respiration. Anesthesiology 1966;27:584-90.

4. Scharf SM, Brown R, Saunders N, Green LH. Hemodynamic effects of positive-pressure inflation. J Appl Physiol Respir Environ Exerc Physiol 1980;49:124-31.

5. Jardin F, Farcot JC, Gueret P, Prost JF, Ozier Y, Bourdarias JP. Cyclic changes in arterial pulse during respiratory support. Circulation 1983;68:266-74.

6. Michard F, Teboul JL. Using heart-lung interactions to assess fluid responsiveness during mechanical ventilation. Crit Care 2000;4:282-9.

7. Zhang Z, Lu B, Sheng X, Jin N. Accuracy of stroke volume variation in predicting fluid responsiveness: A systematic review and meta-analysis. J Anesth 2011;25:904-16.

8. Berkenstadt H, Margalit N, Hadani M, Friedman Z, Segal E, Villa Y, et al. Stroke volume variation as a predictor of fluid responsiveness in patients undergoing brain surgery. Anesth Analg 2001;92:984-9.

9. Coyle JP, Teplick RS, Long MC. Respiratory variations in systemic arterial pressure as an indicator of volume status. Anesthesiology 1983;59:A53.

10. Deflandre E, Bonhomme V, Hans P. Delta down compared with delta pulse pressure as an indicator of volaemia during intracranial surgery. Br J Anaesth 2008;100:245-50.

11. Durga P, Jonnavittula N, Muthuchellappan R, Ramachandran G. Measurement of systolic pressure variation during graded volume loss using simple tools on Datex Ohmeda $\mathrm{S} / 5$ monitor. J Neurosurg Anesthesiol 2009;21:161-4.

12. Qiao H, Zhang J, MD, Liang WM. Validity of pulse pressure and systolic blood pressure variation data obtained from a Datex Ohmeda S/5 monitor for predicting fluid responsiveness during surgery. J Neurosurg Anesthesiol 2010;22:316-22.

13. Charron C, Fessenmeyer C, Cosson C, Mazoit JX, Hebert JL, Benhamou D, et al. The influence of tidal volume on the dynamic variables of fluid responsiveness in critically ill patients. Anesth Analg 2006;102:1511-7.

14. De Backer D, Heenen S, Piagnerelli M, Koch M, Vincent JL. Pulse pressure variations to predict fluid responsiveness: Influence of tidal volume. Intensive Care Med 2005;31:517-23.

15. Vistisen ST, Koefoed-Nielsen J, Larsson A. Should dynamic parameters for prediction of fluid responsiveness be indexed to the tidal volume? Acta Anaesthesiol Scand 2010;54:191-8.

16. Muller L, Louart G, Bousquet PJ, Candela D, Zoric L, de La Coussaye JE, et al. The influence of the airway driving pressure on pulsed pressure variation as a predictor of fluid responsiveness. Intensive Care Med 2010;36:496-503.

17. De Backer D, Taccone FS, Holsten R, Ibrahimi F, Vincent JL. Influence of respiratory rate on stroke volume variation in mechanically ventilated patients. Anesthesiology 2009;110:1092-7.

18. Westphal GA, Gonçalves AR, Bedin A, Steglich RB, Silva E, Poli-de-Figueiredo LF. Vasodilation increases pulse pressure variation, mimicking hypovolemic status in rabbits. Clinics (Sao Paulo) 2010;65:189-94.

19. Radhakrishnan M, Mohanvelu K, Veena S, Sripathy G, Umamaheswara Rao GS. Pulse-plethysmographic variables in hemodynamic assessment during mannitol infusion. J Clin Monit Comput 2012;26:99-106.

20. Gouvêa G, Gouvêa FG. Measurement of systolic pressure variation on a Datex AS/3 monitor. Anesth Analg 2005;100:1864.

21. Poelaert JI, Schüpfer G. Hemodynamic monitoring utilizing transesophageal echocardiography: The relationships among pressure, flow, and function. Chest 2005;127:379-90.

22. Rubin A. Statistics for Evidence-based Practice and Evaluation. $3^{\text {rd }}$ ed. New Delhi: Cengage Learning; 2012. p. 215.

23. Chatterjee N, Koshy T, Misra S, Suparna B. Changes in left ventricular preload, afterload, and cardiac output in response to a single dose of mannitol in neurosurgical patients undergoing craniotomy: A transesophageal echocardiographic study. J Neurosurg Anesthesiol 2012;24:25-9.

24. Sabharwal N, Rao GS, Ali Z, Radhakrishnan M. Hemodynamic changes after administration of mannitol measured by a noninvasive cardiac output monitor. J Neurosurg Anesthesiol 2009;21:248-52.

25. Willerson JT, Curry GC, Atkins JM, Parkey R, Horwitz LD. Influence of hypertonic mannitol on ventricular performance and coronary blood flow in patients. Circulation 1975;51:1095-100.

26. Lundvall J, Mellander S, White T. Hyperosmolality and vasodilatation in human skeletal muscle. Acta Physiol Scand 1969;77:224-33.

27. Coriat P, Vrillon M, Perel A, Baron JF, Le Bret F, Saada M, et al. A comparison of systolic blood pressure variations and echocardiographic estimates of end-diastolic left ventricular size in patients after aortic surgery. Anesth Analg 1994;78:46-53.

28. Biais M, Nouette-Gaulain K, Roullet S, Quinart A, Revel P, Sztark F. A comparison of stroke volume variation measured by Vigileo/FloTrac system and aortic Doppler echocardiography. Anesth Analg 2009;109:466-9.

29. Flachskampf FA, Badano L, Daniel WG, Feneck RO, Fox KF, Fraser AG, et al. Recommendations for transoesophageal echocardiography: Update 2010. Eur J Echocardiogr 2010;11:557-76.

30. Perrino AC Jr., Harris SN, Luther MA. Intraoperative determination of cardiac output using multiplane transesophageal echocardiography: A comparison to thermodilution. Anesthesiology 1998;89:350-7. 